\title{
Glycation-dependent, Reactive Oxygen Species-mediated Suppression of the Insulin Gene Promoter Activity in HIT Cells
}

\author{
Taka-aki Matsuoka, ${ }^{*}$ Yoshitaka Kajimoto, ${ }^{*}$ Hirotaka Watada, ${ }^{*}$ Hideaki Kaneto, ${ }^{*}$ Michihiko Kishimoto, ${ }^{*}$ Yutaka Umayahara, \\ Yoshio Fujitani, ${ }^{\star}$ Takenobu Kamada, ${ }^{*}$ Ryuzo Kawamori, ${ }^{\ddagger}$ and Yoshimitsu Yamasaki ${ }^{*}$ \\ *First Department of Medicine, Osaka University School of Medicine, Suita 565; and Department of Medicine, Endocrinology and \\ Metabolism, Juntendo University School of Medicine, Tokyo 113, Japan
}

\begin{abstract}
Prolonged poor glycemic control in non-insulin-dependent diabetes mellitus patients often leads to a decline in insulin secretion from pancreatic $\beta$ cells, accompanied by a decrease in the insulin content of the cells. As a step toward elucidating the pathophysiological background of the socalled glucose toxicity to pancreatic $\beta$ cells, we induced glycation in HIT-T15 cells using a sugar with strong deoxidizing activity, D-ribose, and examined the effects on insulin gene transcription. The results of reporter gene analyses revealed that the insulin gene promoter is more sensitive to glycation than the control $\beta$-actin gene promoter; $\sim 50$ and $80 \%$ of the insulin gene promoter activity was lost when the cells were kept for $3 \mathrm{~d}$ in the presence of 40 and $60 \mathrm{mM}$ D-ribose, respectively. In agreement with this, decrease in the insulin mRNA and insulin content was observed in the glycationinduced cells. Also, gel mobility shift analyses using specific antiserum revealed decrease in the DNA-binding activity of an insulin gene transcription factor, PDX-1/IPF1/STF-1. These effects of D-ribose seemed almost irreversible but could be prevented by addition of $1 \mathrm{mM}$ aminoguanidine or $10 \mathrm{mM} N$-acetylcysteine, thus suggesting that glycation and reactive oxygen species, generated through the glycation reaction, serve as mediators of the phenomena. These observations suggest that protein glycation in pancreatic $\beta$ cells, which occurs in vivo under chronic hyperglycemia, suppresses insulin gene transcription and thus can explain part of the $\beta$ cell glucose toxicity. (J. Clin. Invest. 1997. 99:144150.) Key words: gene expression regulation - transcription factors - glycosylation - homeodomain protein • oxidative stress
\end{abstract}

\section{Introduction}

Although glucose is the major physiologic stimulator of insulin secretion and biosynthesis in vivo, prolonged exposure of pancreatic $\beta$ cells to high glucose levels is known to cause $\beta$ cell dysfunction $(1,2)$. Histologically, such damaged $\beta$ cells often

Address correspondence to Dr. Yoshitaka Kajimoto, First Department of Medicine, Osaka University School of Medicine, 2-2 Yamadaoka, Suita City, Osaka Pref. 565, Japan. Phone: 81-6-879-3633; FAX: 81-6-879-3639.

Received for publication 5 August 1996 and accepted in revised form 22 October 1996.

J. Clin. Invest.

(C) The American Society for Clinical Investigation, Inc. 0021-9738/97/01/0144/07 \$2.00

Volume 99, Number 1, January 1997, 144-150 reveal extensive degranulation, thus suggesting impaired insulin biosynthesis as a cause of the phenomenon (3). The clinical significance of this phenomenon is supported by the association between the development of diabetes and the substantial reduction of insulin content in $\beta$ cells in model animals with non-insulin-dependent diabetes mellitus (NIDDM) ${ }^{1}(4,5)$.

Despite the fact that glucose toxicity has long been a wellrecognized clinical concept, its biochemical background is poorly understood. While technical difficulties have prevented extensive in vivo research, a line of in vitro studies using $\beta$ cell-derived HIT-T15 cells that were kept under high glucose conditions for a very long period ( $\geq 25$ passages) has provided useful information as to the possible mechanisms underlying the decrease in insulin biosynthesis (6-9). According to the results of those studies, long-term exposure to high glucose concentration caused the HIT-T15 cells to suppress insulin gene promoter activity, and led to decreases in insulin mRNA amount, insulin content, and capacity for insulin secretion. These observations support the idea that reduction of the promoter activity may play a primary role in the impairment of insulin biosynthesis and suggest the potential usefulness of such in vitro systems for the study of the molecular aspects of $\beta$ cell glucose toxicity.

To enable effective prevention and treatment of glucose toxicity to $\beta$ cells, it would be essential to understand the biochemical aspects of the phenomenon. In terms of glucoseinduced cell damage, several possible mechanisms have been proposed to date, including increased osmolarity, an activated sorbitol pathway, and an activated glycation reaction $(10,11)$. Among them, glycation seems to have broad pathological significance: various glycated proteins such as glycosylated hemoglobin, albumin, and lens crystalline are nonenzymatically produced through the Maillard reaction (12-14). These can be observed even under physiological conditions in vivo, but they increase under hyperglycemic conditions $(12,13,15)$. In diabetic animals, glycation is observed extensively in various organs and tissues including the kidney, liver, brain, and lung (12, 16). During the Maillard reaction, which in turn produces Schiff base, Amadori product and advanced glycosylation end products (AGE), reactive oxygen species (ROS) are also produced, and this is suggested to be involved in tissue damage $(17,18)$.

In the present study, we examined the possible effects of glycation on insulin gene transcription using a sugar with powerful reducing activity, D-ribose $(19,20)$. Co-use of aminoguanidine, which binds to the Amadori product or 3-deoxy-

1. Abbreviations used in this paper: AGE, advanced glycosylation end products; NAC, $N$-acetylcysteine; NIDDM, non-insulin-dependent diabetes mellitus; ROS, reactive oxygen species; RSV-LTR, Rous sarcoma virus long terminal repeat. 
glucosone and inhibits the glycation reaction $(21,22)$, and $N$-acetylcysteine (NAC), an antioxidant $(23,24)$, allowed us to show that glycation and the consequent increase of ROS are potential suppressors of the insulin gene promoter. Significant reduction of the DNA-binding activity of a transcription factor, PDX-1/IPF1/STF-1 $(25,26)$, was also observed in glycation-induced cells, suggesting that the high sensitivity of the insulin gene transcription factors to glycation or ROS may underlie the suppression of the insulin gene promoter activity.

\section{Methods}

Materials. Restriction enzymes, DNA polymerases, and other modification enzymes were purchased from commercial suppliers (Toyobo, Tokyo, Japan; Takara, Kyoto, Japan; Stratagene, San Diego, CA; Promega Biotec, Madison, WI; New England Biolabs, Beverly, MA), and radioisotopes were from Amersham Japan (Tokyo, Japan). Tissue culture media were purchased from Nakalai Tesque (Tokyo, Japan), and FBS was from ICN Biomedicals, Inc. (Costa Mesa, CA). Oligonucleotides were synthesized with a DNA/RNA synthesizer (model 394; Applied Biosystems, Tokyo, Japan). Basic laboratory procedures were performed according to standard protocols (27), unless otherwise stated.

Cell culture and gene transfer studies. $\beta$ cell-derived cell line HITT15 cells (No. 1777; American Type Culture Collection, Rockville, MD) were grown in RPMI-1640 medium supplemented with $10 \%$ heat-inactivated FBS, penicillin and streptomycin. The HIT-T15 cells used in this study were passage 70-75, and they retained glucoseresponsive insulin gene transcription and secretion. The plasmids used in reporter gene analyses were pA3RSVLuc (28), containing the Rous sarcoma virus long terminal repeat (RSV-LTR), pHßLuc (29), containing the $4.3-\mathrm{kb}$ fragment of the human $\beta$-actin gene promoter, and pA3InsLuc (30), containing 326-bp 5'-flanking sequences of human insulin gene. pA3RSVLuc was a generous gift from Drs. W.M. Wood (University of Colorado Health Science Center, Denver, CO) and D.R. Helinski (University of California, San Diego, CA), and pH $\beta$ Luc was from Drs. M.A. Barry and S.A. Johnston (University of Texas Southwestern Medical Center, Dallas, TX). $24 \mathrm{~h}$ before gene transfection, HIT-T15 cells were replated in six-well tissue culture plates. $1 \mu \mathrm{g}$ of each reporter plasmid was transfected into the cells by the lipofection method using LipofectAMINE ${ }^{\mathrm{TM}}$ reagent (Life Technologies, Tokyo, Japan) under the conditions recommended by the manufacturer.

For evaluation of promoter activities, HIT-T15 cells were transfected with the pA3InsLuc, $\mathrm{pH} \beta$ Luc, or pA3RSVLuc plasmid and grown for $78 \mathrm{~h}$, followed by harvest of cell lysates and luciferase assays. When required, 40 or $60 \mathrm{mM}$ D-ribose was added to the media $6 \mathrm{~h}$ after transfection. In some of the experiments, $1 \mathrm{mM}$ aminoguanidine or $10 \mathrm{mM}$ NAC was also added. Luciferase activities were normalized with respect to protein concentrations of the cell lysates, and the results were presented as relative luciferase activity with that in D-ribose-untreated HIT cells arbitrarily set at $100 \%$.

Northern blot analyses of insulin $m R N A$. Northern blots followed standard procedures (27) using $10 \mu \mathrm{g}$ total RNA. Total RNA was isolated from HIT-T15 cells that had been kept for $5 \mathrm{~d}$ under 0 , 40, or 60 $\mathrm{mM}$ D-ribose with or without addition of $1 \mathrm{mM}$ aminoguanidine or $10 \mathrm{mM}$ NAC. For the purpose of examining the reversibility of the D-ribose effects on the cells, HIT-T15 cells were kept for $5 \mathrm{~d}$ under 40 $\mathrm{mM}$ D-ribose and then without D-ribose for 2 or $5 \mathrm{~d}$. The hybridization probe was a 408-bp mouse insulin II cDNA isolated from the plasmid pMIn2C (31) and was a kind gift from Drs. J.M. Chirgwin (University of Texas Health Science Center, San Antonio, TX) and M.A. Permutt (Washington University School of Medicine, St. Louis, MO).

Insulin content determination. HIT-T15 cells that had been kept for $5 \mathrm{~d}$ under 0 or $40 \mathrm{mM}$ D-ribose were harvested and extracted for $24 \mathrm{~h}$ at $4^{\circ} \mathrm{C}$ in acid-ethanol. Insulin in the extracts was assayed by ra- dioimmunoassay using a rodent insulin as a standard. Total protein in the extracts was measured using a protein assay (Bio Rad Laboratories, Richmond, CA) and the BSA standard. Insulin concentration was normalized with respect to protein concentration.

Preparation of nuclear extracts and gel mobility shift analyses. Following the procedure described by Sadowski and Gilman (32), nuclear extracts were prepared from HIT-T15 cells kept for $5 \mathrm{~d}$ in media containing 0,40 , or $60 \mathrm{mM}$ D-ribose with or without the addition of $1 \mathrm{mM}$ aminoguanidine or $10 \mathrm{mM}$ NAC. For the purpose of examining the reversibility of the D-ribose effects on the cells, HIT-T15 cells were kept for $5 \mathrm{~d}$ under $40 \mathrm{mM}$ D-ribose and then without D-ribose for 2 or $5 \mathrm{~d} .3 \mu \mathrm{g}$ of each nuclear extract was preincubated with $1 \mu \mathrm{g}$ of poly $(\mathrm{dI}-\mathrm{dC})$ at $4^{\circ} \mathrm{C}$ in a $20-\mu \mathrm{l}$ reaction mixture containing $20 \mathrm{mM}$ Hepes, pH 7.9, $150 \mathrm{mM} \mathrm{NaCl}, 1 \mathrm{mM}$ EDTA, $1 \mathrm{mM}$ DTT and 3\% Ficoll ( vol/vol). $15 \mathrm{~min}$ later, the binding reaction was initiated by adding $100 \mathrm{pg}\left(\sim 10^{4} \mathrm{cpm}\right)$ of $5^{\prime}$ end ${ }^{32} \mathrm{P}$-labeled oligonucleotide probes and, when required, nonradioactive competitor double-stranded oligonucleotides were added, followed by incubation at room temperature for $30 \mathrm{~min}$. When required, $2 \mu \mathrm{l}$ of preimmune serum or anti-PDX-1 (IPF1) antiserum was added to the binding reaction mixtures and these were kept at room temperature for $30 \mathrm{~min}$ before addition of the binding probes. The samples were fractionated on $5 \%$ PAGE precooled to $4^{\circ} \mathrm{C}$ in $0.5 \times$ TBE $(45 \mathrm{mM}$ Tris base, $45 \mathrm{mM}$ boric acid, 1 mM EDTA).

\section{Results}

Sensitivity of insulin gene promoter to glycation. To evaluate the effects of glycation on insulin gene transcription, we examined the insulin gene promoter activity in HIT-T15 cells that had been treated with a sugar with strong reducing activity, D-ribose. Three kinds of fusion gene plasmids, which contained the luciferase reporter linked to the human insulin gene promoter, human $\beta$-actin gene promoter or RSV-LTR promoter, were individually transfected into the HIT-T15 cells. The transfected cells were kept for $72 \mathrm{~h}$ with or without D-ribose and were then harvested for luciferase assays. The results shown in Fig. $1 A$ and Table $\mathrm{I}$ indicated that the activity of the insulin gene promoter was suppressed down to $48 \pm 19$ and $18 \pm 6 \%$ of
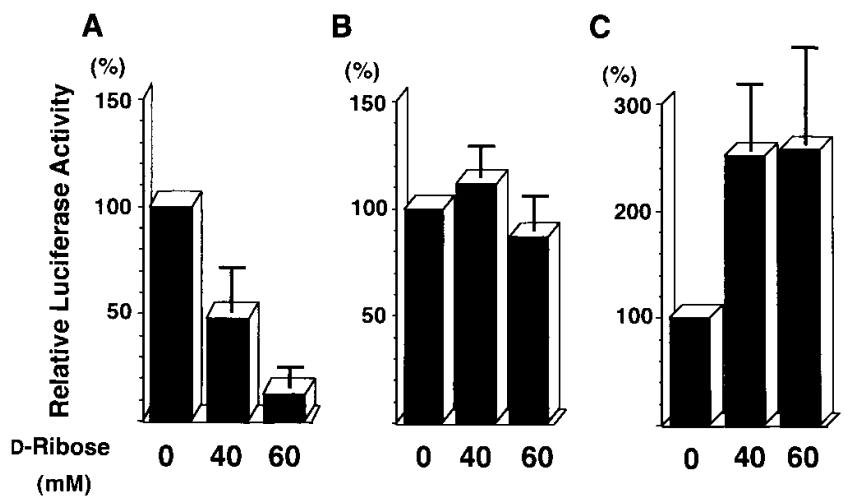

Figure 1. Effects of D-ribose on the insulin gene promoter activity. A reporter gene plasmid containing $(A)$ human insulin gene promoter (30), (B) human $\beta$-actin gene promoter (29), or (C) RSV-LTR promoter (28) was transfected into HIT-T15 cells. $6 \mathrm{~h}$ after the transfection, 40 or $60 \mathrm{mM}$ D-ribose or vehicle only $(0 \mathrm{mM})$ was added to the medium and the cells were cultured for an additional $72 \mathrm{~h}$, followed by harvest of cell lysates, which were then subjected to luciferase assays. Results are presented as relative luciferase activity with that in D-ribose-untreated ( $0 \mathrm{mM})$ HIT cells arbitrarily set at $100 \%$. All data are presented as means \pm SD of at least four individual experiments. 
Table I. Relative Promoter Activity in Various Culture Condition

\begin{tabular}{lccc}
\hline & \multicolumn{3}{c}{ Relative luciferase activity (\%) } \\
\cline { 2 - 4 } \multicolumn{1}{c}{ Medium condition } & Insulin & $\beta$-Actin & RSV-LTV \\
\hline 0 mM D-ribose & 100 & 100 & 100 \\
40 mM D-ribose & $48 \pm 19$ & $112 \pm 12$ & $252 \pm 60$ \\
60 mM D-ribose & $18 \pm 6$ & $87 \pm 14$ & $258 \pm 95$ \\
40 mM D-ribose & & & \\
$\quad+1$ mM aminoguanidine & $108 \pm 10$ & $98 \pm 16$ & $113 \pm 20$ \\
60 mM D-ribose & & & \\
$\quad+1$ mM aminoguanidine & $67 \pm 18$ & $88 \pm 9$ & $139 \pm 52$ \\
40 mM D-ribose & & & \\
$\quad+10$ mM NAC & $104 \pm 10$ & $97 \pm 9$ & $100 \pm 19$ \\
60 mM D-ribose & & & \\
$\quad+10$ mM NAC & $63 \pm 23$ & $86 \pm 10$ & $101 \pm 20$ \\
1 mM aminoguanidine & $100 \pm 15$ & $110 \pm 11$ & $96 \pm 16$ \\
10 mM NAC & $101 \pm 18$ & $103 \pm 19$ & $96 \pm 18$ \\
$\quad$ & & & \\
\hline
\end{tabular}

Values are presented as means $\pm \mathrm{SD}$ of at least four individual experiments.

the control ( $0 \mathrm{mM}$ D-ribose) when the cells were kept in the presence of 40 and $60 \mathrm{mM}$ D-ribose, respectively. No significant changes were observed with the $\beta$-actin gene promoter (112 \pm 12 and $87 \pm 14 \%$ for 40 and $60 \mathrm{mM}$ D-ribose, respectively; Fig. $1 B$ and Table I). In terms of the RSV-LTR promoter, an increase was observed in the presence of 40 and 60 $\mathrm{mM}$ D-ribose (252 \pm 60 and $258 \pm 95 \%$, respectively; Fig. $1 C$ and Table I).

To verify that the suppression of the insulin gene promoter activity by D-ribose is relevant to the induction of glycation by D-ribose, we observed the effects of D-ribose while inhibiting glycation using $1 \mathrm{mM}$ aminoguanidine. The results shown in Fig. $2 A$ revealed that addition of aminoguanidine could lead to complete or partial neutralization of the promoter-suppressing effects $(48 \pm 19$ to $108 \pm 10 \%$ for $40 \mathrm{mM}$ D-ribose; $18 \pm 6$ to $67 \pm 18 \%$ for $60 \mathrm{mM}$ D-ribose; Fig. $2 A$ and Table I). Regarding the RSV-LTR promoter activity, aminoguanidine at least partially blocked the D-ribose-responsive increase of the activity $(252 \pm 60$ to $113 \pm 20 \%$ for $40 \mathrm{mM}$ D-ribose; $258 \pm 95$ to $139 \pm$ $52 \%$ for $60 \mathrm{mM}$ D-ribose; Fig. $2 C$ and Table I). In the absence of D-ribose, aminoguanidine seemed to have no direct effect on the insulin gene promoter as well as $\beta$-actin gene and RSVLTR promoter activities (Fig. 2 and Table I). These neutralizing effects of aminoguanidine suggested that the two contrastive effects of D-ribose, its suppressive effects on the insulin gene promoter and its activating effects on the RSV-LTR promoter, were both mediated by induction of glycation.

Glycation often causes an increase of ROS, which are suggested to play a primary role in glycation-induced tissue damage $(18,33)$. Also, the RSV-LTR promoter, which was activated by D-ribose in a glycation-dependent manner (Figs. 1 and 2 and Table I), is known to be a target of ROS-induced activation through the cis-acting motif CArG box $(34,35)$. These findings tempted us to consider that ROS induction may also be involved in the D-ribose-induced, glycation-dependent changes in the promoter activities. Accordingly, we inhibited $\mathrm{H}_{2} \mathrm{O}_{2}$ production using $10 \mathrm{mM}$ NAC and examined the effects on the changes in the promoter activities. Similar to the results obtained with aminoguanidine, addition of NAC totally or partially rescued the cells from glycation-dependent reduction of the insulin gene promoter activity ( $48 \pm 19$ to $104 \pm 10 \%$ for 40 $\mathrm{mM}$ D-ribose; $18 \pm 6$ to $63 \pm 23 \%$ for $60 \mathrm{mM}$ D-ribose; Fig. $3 \mathrm{~A}$ and Table I). In terms of the RSV-LTR promoter, the D-riboseinduced promoter activation was totally abolished (252 \pm 60 to $100 \pm 19 \%$ for $40 \mathrm{mM}$ D-ribose; $258 \pm 95$ to $101 \pm 20 \%$ for 60 mM D-ribose; Fig. $3 C$ and Table I). These results indicated that ROS induction mediates the glycation-dependent suppression of the insulin gene promoter as well as the activation of the RSV-LTR promoter.

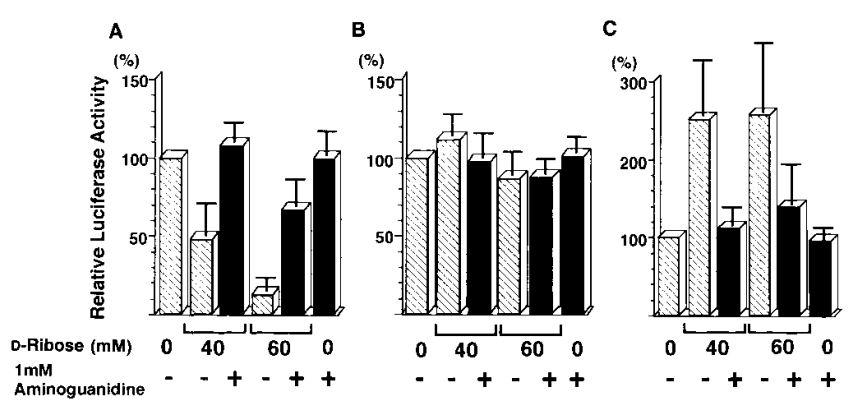

Figure 2. Effects of aminoguanidine on D-ribose-induced suppression of the insulin gene promoter. A reporter gene plasmid containing $(A)$ human insulin gene promoter $(30),(B)$ human $\beta$-actin gene promoter (29), or (C) RSV-LTR (28) was transfected into HIT-T15 cells. $6 \mathrm{~h}$ after the transfection, $1 \mathrm{mM}$ aminoguanidine was added simultaneously with 40,60 , or $0 \mathrm{mM}$ (vehicle only) D-ribose. The cells were cultured for an additional $72 \mathrm{~h}$, followed by harvest of cell lysates, which were then subjected to luciferase assays. Results are presented as relative luciferase activity with that in aminoguanidine- or D-ribose-untreated (vehicle only) HIT-T15 cells arbitrarily set at $100 \%$. All data are presented as means \pm SD of at least four individual experiments. The data described in Fig. 1 are also shown by shaded bars to facilitate comparison.

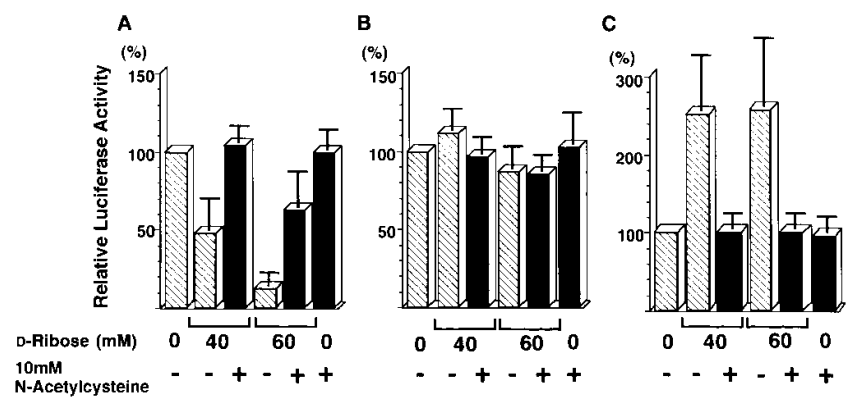

Figure 3. Effects of NAC on D-ribose-induced suppression of the insulin gene promoter. A reporter gene plasmid containing $(A)$ human insulin gene promoter (30), $(B)$ human $\beta$-actin gene promoter (29), or $(C)$ RSV-LTR promoter (28) was transfected into HIT-T15 cells. $6 \mathrm{~h}$ after transfection, $10 \mathrm{mM}$ NAC was added simultaneously with 40,60 , or $0 \mathrm{mM}$ (vehicle only) D-ribose. The cells were cultured for an additional $72 \mathrm{~h}$, followed by harvest of cell lysates, which were then subjected to luciferase assays. Results are presented as relative luciferase activity with that in NAC- or D-ribose-untreated (vehicle only) HIT-T15 cells arbitrarily set at $100 \%$. All data are presented as means \pm SD of at least four individual experiments. The data described in Fig. 1 are also shown by shaded bars to facilitate comparison. 
A
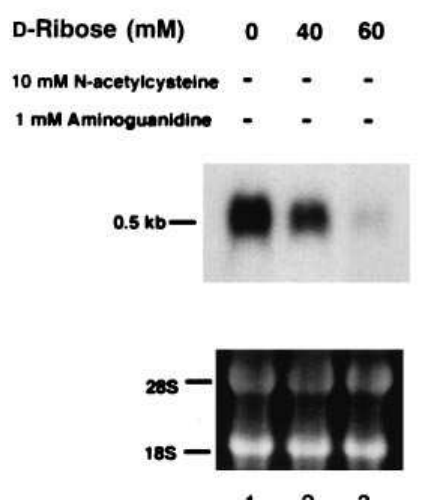

B

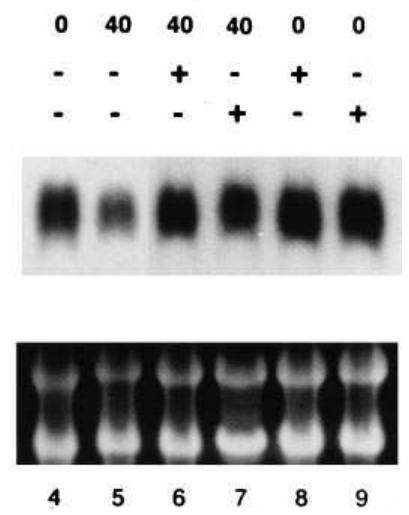

Figure 4. Effects of D-ribose on the amounts of insulin gene transcripts. Northern blot analyses were performed using a mouse insulin II cDNA (31). Each lane contained $10 \mu \mathrm{g}$ total RNA isolated from HIT-T15 cells grown for $5 \mathrm{~d}$ under various conditions. Blot $A$, cells were kept in medium containing $0 \mathrm{mM}$ (vehicle only), $40 \mathrm{mM}$, or 60 $\mathrm{mM}$ D-ribose (lanes 1-3). Blot $B$, the culture medium contained 0 $\mathrm{mM}$ (vehicle only; lanes 4, 8, and 9) or $40 \mathrm{mM}$ (lanes 5-7) D-ribose along with $10 \mathrm{mM}$ NAC (lanes 6 and 8 ) or $1 \mathrm{mM}$ aminoguanidine (lanes 7 and 9). In lanes where aminoguanidine or NAC was not added, their vehicles were added instead. The exposure time was $24 \mathrm{~h}$ for both blots. Similar results were obtained in two independent experiments.

Glycation-dependent reduction of insulin mRNA amount and insulin content. To examine whether the glycation-dependent suppression of the insulin gene promoter caused the reduction of its transcripts, insulin mRNA levels were measured by Northern blot analyses (Fig. 4). Amounts of insulin mRNA, detected as $0.5-\mathrm{kb}$ bands on the blots, decreased when the HIT-T15 cells were kept for $5 \mathrm{~d}$ with $40 \mathrm{mM}$ D-ribose (Fig. 4, lane 2). Further decrease was observed when they were kept with $60 \mathrm{mM}$ D-ribose (Fig. 4, lane 3). Also in agreement with the observations on promoter activities, $1 \mathrm{mM}$ aminoguanidine and $10 \mathrm{mM} \mathrm{NAC}$ neutralized the suppressive effects of D-ribose (Fig. 4, lanes 4-9).

We also checked for possible changes in insulin content. In agreement with the decrease in insulin mRNA, the insulin content of cells cultured in the presence of $40 \mathrm{mM}$ D-ribose for $5 \mathrm{~d}$ was $41 \pm 6 \mathrm{pmol} / \mathrm{mg}$ protein (average $\pm \mathrm{SD} ; n=5$ ), which was only $18 \%$ of that of the control cells kept for the same period without D-ribose ( $229 \pm 52 \mathrm{pmol} / \mathrm{mg}$ protein; $n=5)$. Thus, the glycation-dependent suppression of the insulin gene promoter seemed to have reduced the amount of its transcript and protein in the cells.

Glycation-dependent reduction of DNA-binding activity of $P D X-1$. To obtain clues to understanding the molecular basis of the suppression of insulin gene promoter activity, we examined the possible glycation-induced changes in the activity of a transcription factor of the insulin gene, PDX-1/IPF1/STF-1. Using the human A3 region as a binding probe, gel mobility shift analyses were performed. Before evaluating the effects of glycation, the specificity of the binding to the probe was verified using an anti-PDX-1 (IPF1) antiserum (30), wild and mutated competitors, and the hUPE3 competitor reproducing the hUPE3 site of the human glucokinase gene promoter, which we recently showed can bind PDX-1 (Fig. $5 C$ and reference 30 ). The supershift of the band (lane 2), as well as specific competition by the competitors (lanes 4-6), demonstrated that PDX-1 in HIT cells specifically binds to the human A3 probe.

The effects of glycation on the DNA-binding activity of PDX-1 were evaluated in Fig. 5, $A$ and $B$. When cells were kept for $5 \mathrm{~d}$ with 40 or $60 \mathrm{mM}$ D-ribose, marked reduction of PDX-1 binding to the A3 probe was observed (Fig. $5 A$ ). However, coexistence of $1 \mathrm{mM}$ aminoguanidine or $10 \mathrm{mM}$ NAC in the media prevented the effects of D-ribose (Fig. $5 \mathrm{~B}$, lanes 3 and 4). In the absence of D-ribose, aminoguanidine or NAC alone had no effect on the PDX-1 activity. These results indicated that D-ribose suppressed the DNA-binding activity of PDX-1 in a manner dependent on glycation and ROS.

Reversibility of the effects of D-ribose. To investigate whether the D-ribose effects on the insulin gene transcription in HIT-T15 cells are reversible or not, we kept the cells under $40 \mathrm{mM}$ D-ribose for $5 \mathrm{~d}$ and then started culturing the cells in media containing no D-ribose. Total RNA and nuclear extracts were prepared from those cells at $2 \mathrm{~d}$ and $5 \mathrm{~d}$ after D-ribose was eliminated, and Northern blot analyses and gel mobility shift analyses were performed. As shown in Fig. 6, there was only slight recovery from the decrease in the insulin mRNA amounts caused by $40 \mathrm{mM}$ D-ribose, even after the cells were kept in D-ribose-free medium for $5 \mathrm{~d}$. Similarly, 5-d culture in D-ribose-free medium did not lead to recovery of the normal DNA-binding activity for PDX-1 (Fig. 7). These observations suggest that the changes that occurred in the HIT-T15 cells because of the D-ribose-induced glycation and ROS are almost, if not totally, irreversible.

\section{Discussion}

Under hyperglycemia, the production of various reducing sugars such as glucose, glucose-6-phosphate, and fructose increases through glycolysis and the polyol pathway. All of these reducing sugars are known to promote glycation reactions of various proteins $(19,36)$. In line with these facts, an increase in AGE was detected in various tissues of streptozotocin-induced diabetic rats (16). The pancreatic $\beta$ cells, which express the high $K_{\mathrm{m}}$ glucose transporter GLUT2 abundantly and thereby display highly efficient glucose uptake when exposed to high glucose concentration, were recently shown to contain AGE (37), providing support for the idea that glycation reaction may underlie the glucose toxicity to $\beta$ cells.

In the present study, we established an in vitro model cell system that allows us to evaluate the potential effects of glycation and the consequent increase of ROS on the $\beta$ cell function. Among reducing sugars that potentially induce glycation, D-ribose is outstanding for its very potent activity and thus is often used in in vitro studies as an inducer of glycation $(19,20)$. The use of D-ribose in this study could induce glycation in HIT-T15 cells during a relatively short period $(<72 \mathrm{~h})$ between the transfection of the reporter gene plasmids and harvest of the cellular extracts. This made it possible to show that glycation, at least when induced in HIT-T15 cells, suppresses the insulin gene promoter (Figs. 1 and 2). In agreement with this decrease in the promoter activity, we observed decreases in the insulin mRNA (Fig. 4) and insulin content, supporting the idea that glycation and ROS-dependent suppression of the insulin gene promoter caused impairment of insulin synthesis in HIT-T15 cells. 
A

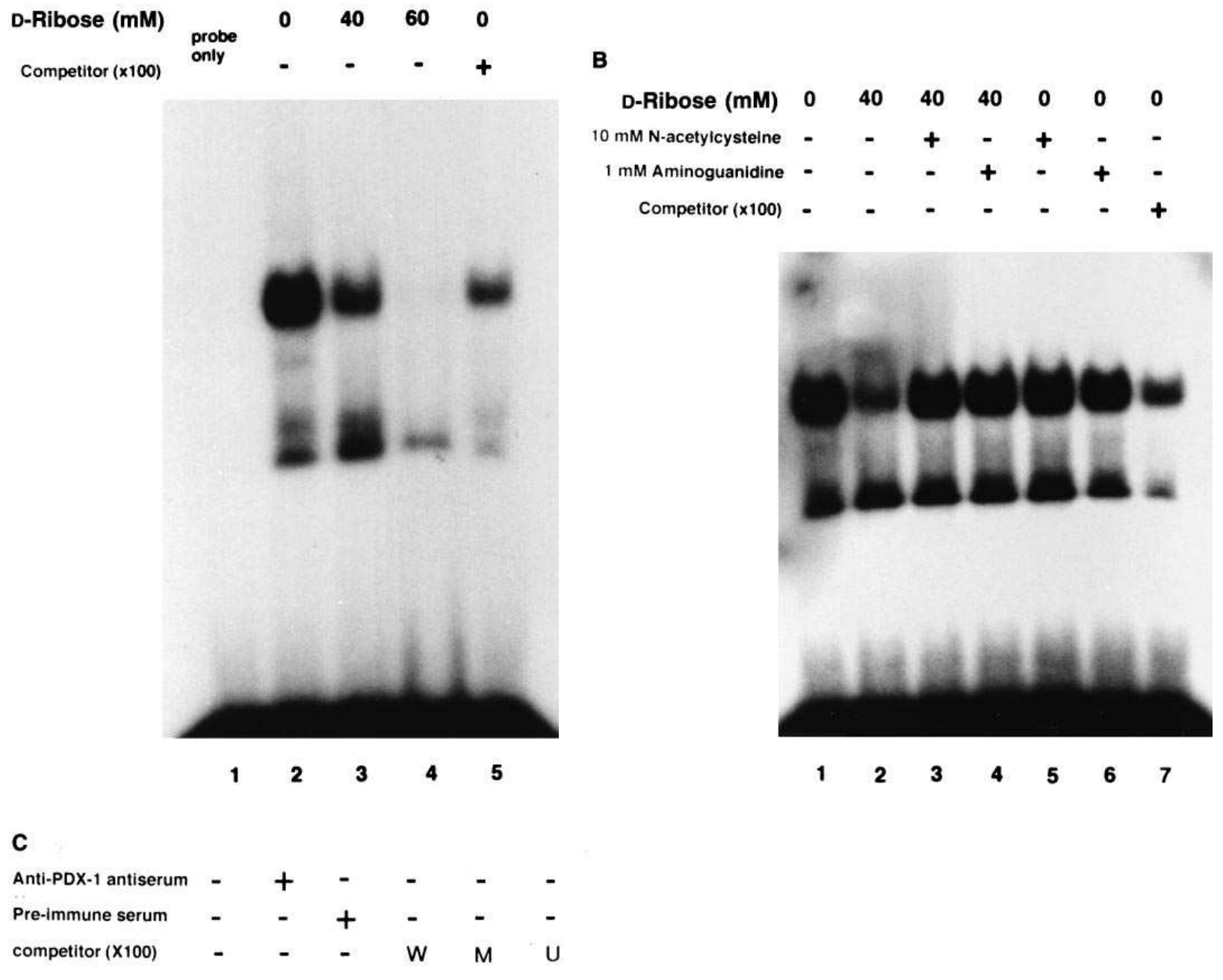

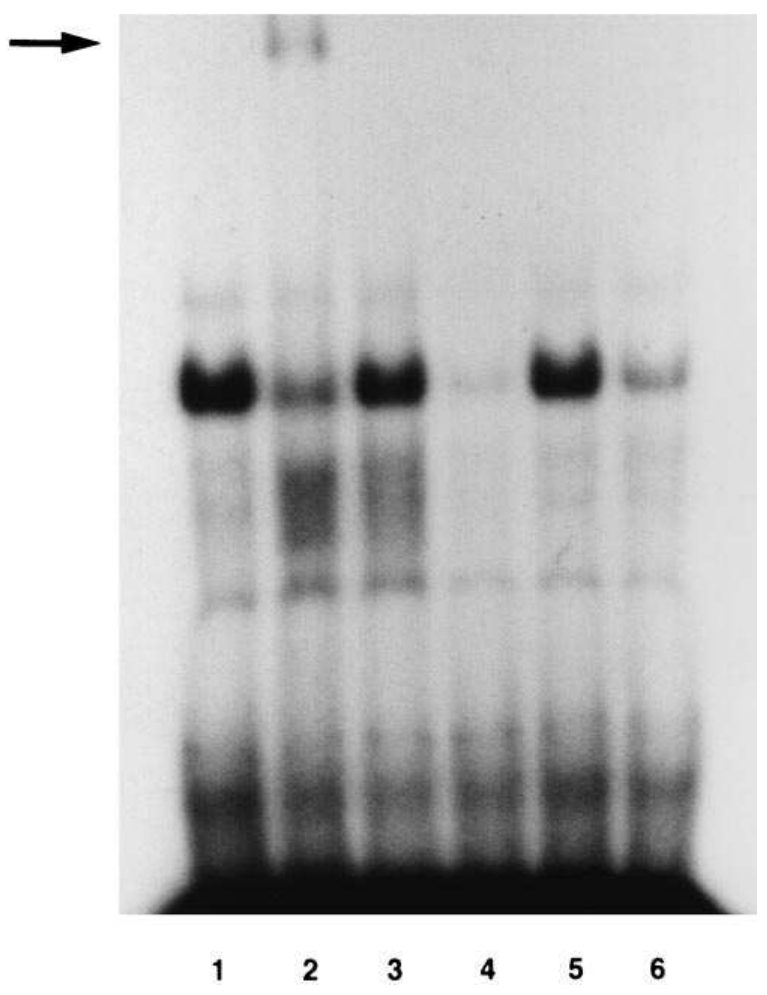

Figure 5. Effects of D-ribose on the DNA-binding activity of PDX-1. Gel-mobility shift analyses were performed to evaluate possible effects of D-ribose on the DNA-binding activity of PDX-1. A doublestranded oligonucleotide reproducing the human insulin gene A3 region and surrounding sequences (-201 to -224; 5'-GTTAAGACTCTAATGACCCGCTGG-3') was used as a binding probe. $(A)$ Nuclear extracts were prepared from HIT-T15 cells kept for $5 \mathrm{~d}$ in medium containing $0 \mathrm{mM}$ (vehicle only), $40 \mathrm{mM}$, or $60 \mathrm{mM}$ D-ribose (lanes 2-4). Lane 5 was the same as lane 2, except that 100-fold excess of unlabeled competitor was added. Lane 1 included no nuclear extract. $(B)$ Nuclear extracts prepared from cells kept for $5 \mathrm{~d}$ in $0 \mathrm{mM}$ (vehicle only) or $40 \mathrm{mM}$ D-ribose with or without the coexistence of 1 mM NAC (lanes 4 and 6) or $10 \mathrm{mM}$ aminoguanidine (lanes 3 and 5) were used. In lane 7, 100-fold excess of unlabeled competitor was added. $(C)$ The specificity and identity of the DNA-binding complex were analyzed. Anti-PDX-1 (IPF1) antiserum (lane 2) or preimmune serum (lane 3 ) was added to the binding reaction before addition of the probe. The binding specificity was evaluated using the unlabeled wild-type ( $W$, lane 4$)$, mutated-type $\left(M, 5^{\prime}\right.$-GTTAAGACTACGCGTACCCGCTGG-3', lane 5), and hUPE3 ( $U$ [reference 30], lane 6 ) competitor. The arrow indicates the supershifted band. Similar results were obtained in at least two independent experiments. 


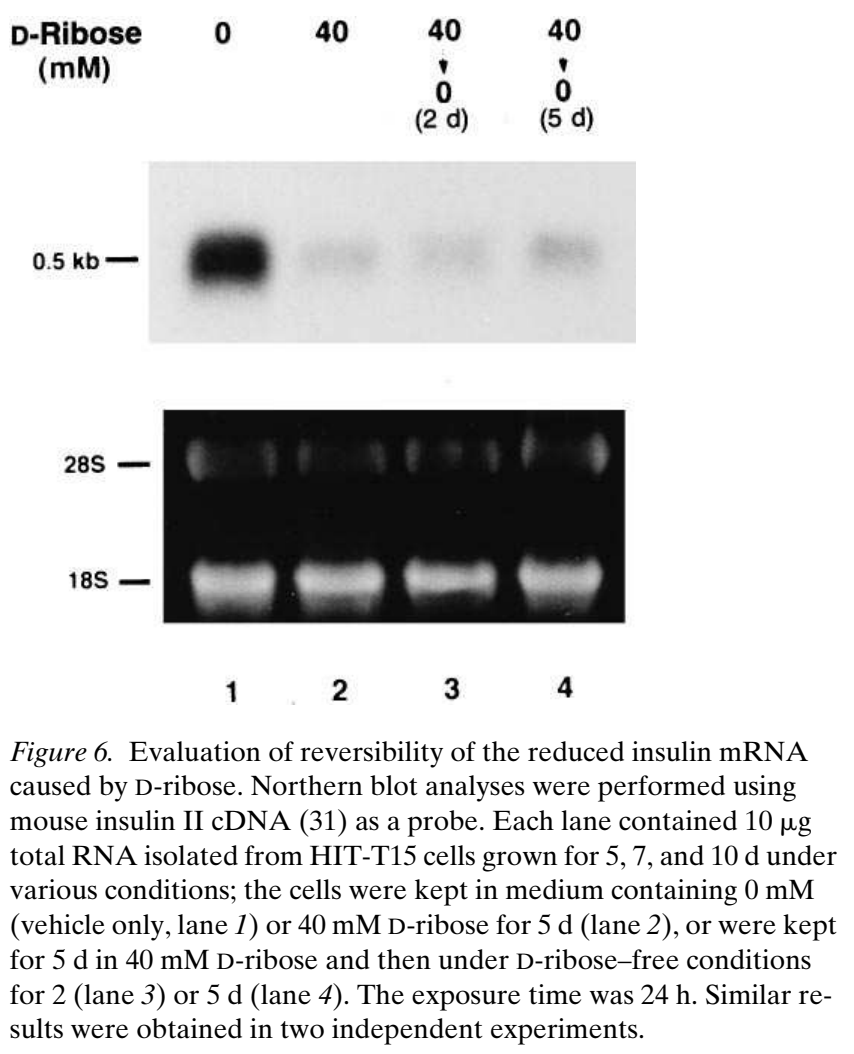

Use of NAC allowed us to show the involvement of ROS in glycation-dependent suppression of the insulin gene promoter. Lines of evidence have suggested to date that ROS, which are known to be induced in vivo when reducing sugars or unsaturated lipids are increased, may cause oxidative stress and damage to proteins in diabetes $(18,33)$. Although the ROS that caused suppression of the insulin gene promoter in our present study were artificially induced by D-ribose, ROS can be physiologically generated by reducing sugars or unsaturated lipids in vivo, and may cause similar phenomena in diabetes.

We should note that, as could be expected from the strong deoxidizing activity, D-ribose caused reduction in cell viability. In proportion to the D-ribose concentration, the speed of cell growth decreases; when cells were cultured for $72 \mathrm{~h}$ in 40 and $60 \mathrm{mM}$ D-ribose, cell numbers increased 2.6- and 1.3-fold, respectively, which were smaller than the 3.3-fold increase observed when they were kept without D-ribose. Microscopically, after the 72-h culture with D-ribose, there were some cells whose attachment to the plate appeared to be loose. These effects of D-ribose were almost totally prevented by addition of $1 \mathrm{mM}$ aminoguanidine or $10 \mathrm{mM}$ NAC (Matsuoka, T., and Y. Kajimoto, unpublished observations). Although the pathophysiological significance of these phenomena is not known, such inhibitory effects of glycation or ROS on cell growth or survival may explain in part the $\beta$ cell glucose toxicity. However, we assume that the suppressive effect on the promoter activity, which was observed for the insulin gene but not for the $\beta$-actin gene, should be taken as an event that is distinguishable from the effects on cell viability. The clear difference in the responses to D-ribose between the insulin gene and $\beta$-actin gene promoters suggested that the suppression of the promoter activity should be attributed to impairment of specific

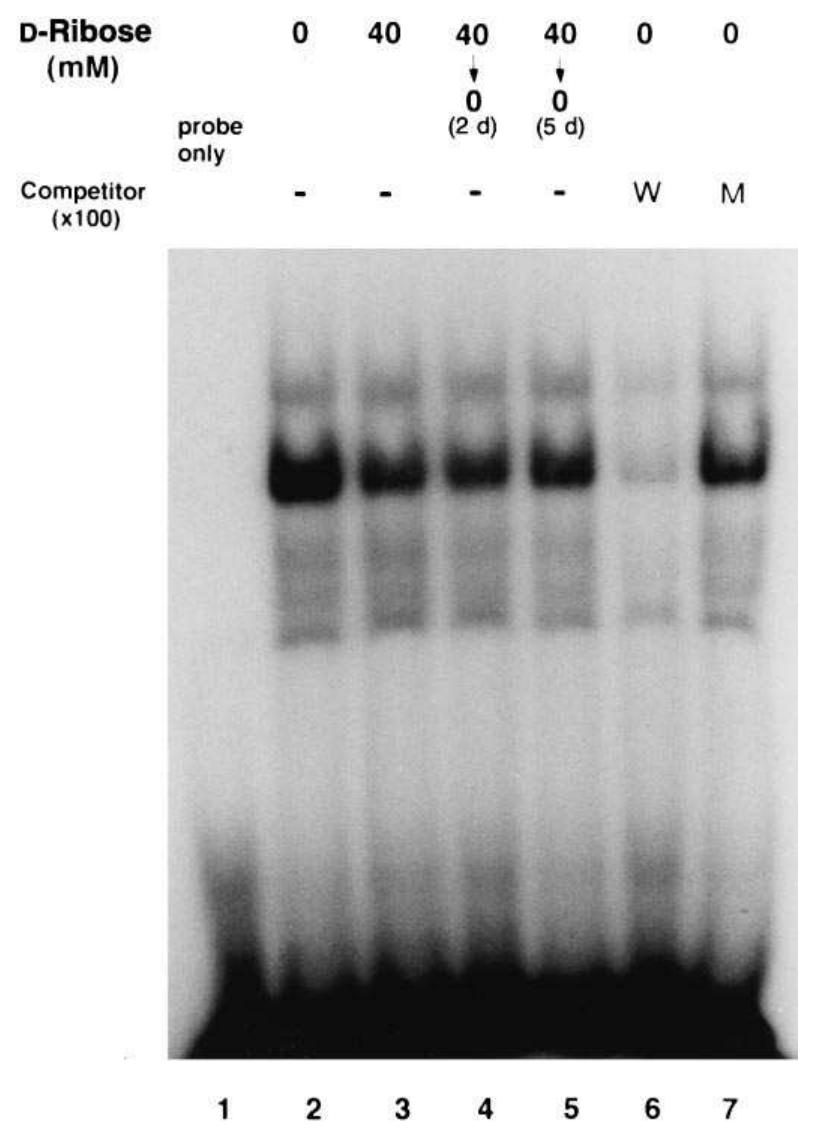

Figure 7. Evaluation of reversibility of the reduced PDX-1 activity caused by D-ribose. Gel mobility shift analyses were performed to evaluate the reversibility of the reduction in PDX-1 activity caused by D-ribose. The binding probe for the human insulin gene $\mathrm{A} 3$ region was the same as in Fig. 2. Nuclear extracts were prepared from HITT15 cells grown for 5, 7, and $10 \mathrm{~d}$ under various conditions; the cells were kept in medium containing $0 \mathrm{mM}$ (vehicle only, lane 2) or 40 $\mathrm{mM}$ D-ribose for $5 \mathrm{~d}$ (lane 3), or were kept for $5 \mathrm{~d}$ in $40 \mathrm{mM}$ D-ribose and then under D-ribose-free conditions for 2 (lane 4 ) or $5 \mathrm{~d}$ (lane 5). The binding specificity was evaluated using the unlabeled wild-type $(W$, lane 6$)$, and mutated type ( $M$, lane 7 ) competitors that are described in Fig. 5. Lane 1 was the lane in which no nuclear extract was used. Similar results were obtained in two independent experiments.

transcription factors rather than to more generalized events, such as a decrease in general cell viability.

Indirect support of our present observations comes from the previous reports by Olson et al. (8) and Sharma et al. (9), which suggested reduction of PDX-1/IPF1/STF-1 $(25,26)$ activity as a cause of coreduction of the insulin gene promoter activity and mRNA amounts. Their cell model for glucose toxicity was the HIT-T15 cell kept under high glucose concentration for a very long period ( $\geq 25$ passages). Despite the differences in experimental design between their study and ours, we obtained four observations in agreement with respect to insulin gene transcription: suppression of the promoter, decreases in mRNA and in protein, and impairment of PDX-1 activity. The use of aminoguanidine and NAC in their experimental model may provide useful information for understanding the relative physiological significance of glycation or ROS in $\beta$ cell glucose toxicity. Another similarity between their data and ours was the irreversibility of the phenomena (38); the D-ribose- 
dependent suppression of insulin mRNA as well as of the DNA-binding activity of PDX-1 was hardly recovered, even after the cells had been kept for $5 \mathrm{~d}$ without D-ribose (Figs. 6 and 7). Thus it is likely that the suppressive effects of glycation or ROS on the insulin gene transcription, if they keep occurring in vivo, would accumulate in the cells and inhibit insulin synthesis.

Although physiological significance is most evident for PDX-1 whose disruption caused loss of the pancreas in mice (39), several other factors, including RIPE3b1, whose activity also seemed to be inhibited after chronic exposure of HIT cells to high glucose concentrations $(8,9)$, are also involved in regulation of the insulin gene. Accordingly, to clarify all of the aspects of glycation or ROS effects on the insulin gene control machinery, the physiological roles of each transcription factor in determining the transcription rate of insulin gene need to be characterized.

In summary, we showed that glycation and the consequent increase of ROS are potential inhibitors of insulin gene transcription. While increased glycation in various tissues was identified in diabetes in model animals (16) and in humans (15, $40)$, similar phenomena are likely to occur in vivo in islets. The glycation-introduced HIT-T15 cells used in this study may offer a useful model for further understanding the molecular basis of glucose toxicity to pancreatic $\beta$ cells.

\section{Acknowledgments}

We thank Ms. Noriko Fujita for the excellent technical assistance.

This study was supported in part by a Grant-in-Aid for Scientific Research (to R. Kawamori) and grants from Japan Diabetes Foundation (to Y. Kajimoto) and Kyowa Hakko Kogyo Co. Ltd. (to Y. Kajimoto and Y. Yamasaki).

\section{References}

1. Unger, R.H., and S. Grundy. 1985. Hyperglycemia as an inducer as well as a consequence of impaired islets cell function and insulin resistance: implications for the management of diabetes. Diabetologia. 28:119-121.

2. Robertson, R.P. 1989. Type II diabetes, glucose "non-sense," and islet desensitization. Diabetes. 38:1501-1505.

3. Eizirik, D.L., G.S. Korbutt, and C. Hellerstrom. 1992. Prolonged exposure of human pancreatic islets to high glucose concentration in vitro impairs the $\beta$-cell function. J. Clin. Invest. 90:1263-1268.

4. Tokuyama, Y., J. Sturis, A.M. DePaoli, J. Takeda, M. Stroffel, J. Tang, X. Sun, K.S. Polonsky, and G.I. Bell. 1995. Evolution of $\beta$-cell dysfunction in the male Zucker diabetic fatty rat. Diabetes. 44:1447-1457.

5. Hummel, K.P., D.L. Coleman, and P.W. Lane. 1972. The Influence of genetic background of expression of mutations at the diabetes locus in the mouse. I. C57BL/KsJ and C57BL/6J strains. Biochem. Genet. 7:1-13.

6. Robertson, R.P., H.J. Zhang, K.L. Pyzdrowski, and T.F. Walseth. 1992. Preservation of insulin mRNA levels and insulin secretion in HIT cells by avoidance of chronic exposure to high glucose concentrations. J. Clin. Invest. 90:320-325.

7. Olson, L.K., J.B. Redmon, H.C. Towle, and P. Robertson. 1993. Chronic exposure of HIT cells to high glucose concentrations paradoxically decreases insulin gene transcription and alters binding of insulin gene regulatory protein. J. Clin. Invest. 92:514-519.

8. Olson, L.K., A. Sharma, M. Peshavaria, C.V.E. Wright, H.C. Towle, R.P. Robertson. and R. Stein. 1995. Reduction of insulin gene transcription in HITT15 $\beta$-cells chronically exposed to a supraphysiologic glucose concentration is associated with loss of STF-1 transcription factor expression. Proc. Natl. Acad. Sci. USA. 92:9127-9131.

9. Sharma, A., L.K. Olson, R.P. Robertson, and R. Stein. 1995. The reduction of insulin gene transcription in HIT-T15 $\beta$ cells chronically exposed to high glucose concentration is associated with loss of RIPE3b1 and STF-1 transcription factor expression. Mol. Endocrinol. 9:1127-1134.

10. Clements, R.S., Jr. 1986. The polyol pathway. A historical review. Drugs. 32(Suppl. 2):3-5.

11. Eble, A.S., S.R. Thorpe, and J.W. Baynes. 1983. Nonenzymatic glucosylation and glucose-dependent cross-linking of protein. J. Biol. Chem. 258:9406-9412.

12. Brownlee, M., H. Vlassara, and A. Cerami. 1984. Nonenzymatic glyco- sylation and the pathogenesis of diabetic complications. Ann. Intern. Med. 101: 527-537.

13. Njoroge, F.J., and V.M. Monnier. 1989. The chemistry of the Maillard reaction under physiological conditions: a review. Prog. Clin. Biol. Res. 304:85-107.

14. Duhaiman, A.S., N. Rabbani, and E. Cotlier. 1990. Camel lens crystallins glycosylation and high molecular weight aggregate formation in the presence of ferrous ions and glucose. Biochem. Biophys. Res. Commun. 173:823-832.

15. Monnier, V.M., R.R. Kohn, and A. Cerami. 1984. Accelerated age-related browning of human collagen in diabetes mellitus. Proc. Natl. Acad. Sci. USA 81:583-587.

16. Myint, T., S. Hoshi, T. Ookawara, N. Miyazawa, K. Suzuki, and N. Taniguchi. 1995. Immunological detection of glycated proteins in normal and streptozotocin-induced diabetic rats using anti hexitol-lysine IgG. Biochim. Biophys. Acta. 1272:73-79.

17. Sakurai, T., and S. Tsuchiya. 1988. Superoxide production from nonenzymatically glycation protein. FEBS Lett. 236:406-410.

18. Baynes, J.W. 1991. Role of oxidative stress in development of complications in diabetes. Diabetes. 40:405-412.

19. Franklin, H.B., and P.J. Higgins. 1981. Reaction of monosaccharides with proteins: possible evolutionary significance. Science (Wash. DC). 213:222-224.

20. Hasegawa, G., A.J. Hunter, and A.S. Charonis. 1995. Matrix nonenzymatic glycosylation leads to altered cellular phenotype and intracellular tyrosine phosphorylation. J. Biol. Chem. 270:3278-3283.

21. Brownlee, M., H. Vlassara, A. Kooney, P. Ulrich, and A. Cerami. 1986. Aminoguanidine prevents diabetes-induced arterial wall protein cross-linking. Science (Wash. DC). 232:1629-1632.

22. Edelstein, D., and M. Brownlee. 1992. Mechanistic studies of advanced glycosylation by aminoguanidine. Diabetes. 41:26-29.

23. Meister, A. 1988. Glutathione metabolism and its selective modification. J. Biol. Chem. 263:17205-17208.

24. Ratan, R.R., T.H. Murphy, and J.M. Baraban. 1994. Macromolecular synthesis inhibitors prevent oxidative stress-induced apoptosis in embrionic cortical neurons by shunting cysteine from protein synthesis to glutathione. $J$. Neurosci. 14:4385-4392.

25. Ohlsson, H., K. Karlsson, and T. Edlund. 1993. IPF1, a homeodomaincontaining transactivator of the insulin gene. EMBO (Eur. Mol. Biol. Organ.) J. 12:4251-4259.

26. Leonard, J., B. Peers, T. Johnson, K. Ferreri, S. Lee, and M.R. Montminy. 1993. Characterization of somatostatin transactivating factor-1, a novel homeobox factor that stimulates somatostatin expression in pancreatic islet cells. Mol. Endocrinol. 7:1275-1283.

27. Sambrook, J., E.F. Fritsch, and T. Maniatis. 1989. Molecular Cloning: A Laboratory Mannual. 2nd Ed. Cold Spring Harbor Laboratory, Cold Spring Harbor, NY.

28. Maxwell, I.H., G.S. Harrison, W.M. Wood, F. Maxwell. 1989. A DNA cassette containing a trimerized SV40 polyadenylation signal which efficiently blocks spurious plasmid-initiated transcription. Biotechniques. 7:276-280.

29. Leavitt, J., P. Gunning, P. Porreca, S.Y. Ng, C.S. Lin, and L. Kedes. 1984. Molecular cloning and characterization of mutant and wild-type human beta-actin genes. Mol. Cell. Biol. 4:1961-1969.

30. Watada, H., Y. Kajimoto, Y. Umayahara, T. Matsuoka, H. Kaneto, Y. Fujitani, T. Kamada, R. Kawamori, and Y. Yamasaki. 1996. The human glucokinase gene $\beta$-cell-type promoter: an essential role of insulin promoter factor 1 (IPF1)/PDX-1 in its activation in HIT-T15 cells. Diabetes. 45:1478-1488.

31. Soares, M.B., E. Schon, A. Henderson, S.K. Karathanasis, R. Cate, S Zeitlin, J. Chirgwin, and A. Efstratiadis. 1985. RNA-mediated gene duplication: the rat preproinsulin I gene is a functional retroposon. Mol. Cell. Biol. 5: 2090-2103.

32. Sadowski, H.B., and M.Z. Gilman. 1993. Cell-free activation of a DNAbinding protein by epidermal growth factor. Nature (Lond.). 362:79-83.

33. Hunt, J.V., R.T. Dean, and S.P. Wolff. 1988. Hydroxyl radical production and autoxidative glycosylation. Biochem. J. 256:205-212.

34. Trouche, D., M. Grigoriev, P. Robin, and A.H. Bellan. 1993. The serum unresponsive Rous sarcoma virus promoter sustains a high serum response factordependent transcription in vitro. Biochem. Biophys. Res. Commun. 196:611-618.

35. Nose, K., M. Shibanuma, K. Kikuchi, H. Kageyama, S. Sakiyama, and T. Kuroki. 1991. Transcriptional activation of early-response genes by hydrogen peroxide in a mouse osteoblastic cell line. Eur. J. Biochem. 201:99-106.

36. Kashimura, N., J. Morita, and T. Komano. 1979. Autoxidation and phagocidal action of some reducing sugar phosphate. Carbohyd. Res. 70:C3-C7.

37. Tajiri, Y., and V.E. Grill. 1996. Advanced glycosylation end products in pancreatic islets: coupling to high glucose exposure and deterioration of $\beta$-cell function. Diabetes. 45(Suppl. 2):195A.

38. Robertson, R.P., L.K. Olson, and H.J. Zhang. 1994. Differentiating glucose toxicity from glucose desensitization: a new message from the insulin gene. Diabetes. 43:1085-1089.

39. Jonsson, J., L. Carlsson, T. Edlund, and H. Edlund. 1984. Insulin-promoter factor 1 is required for pancreas development in mice. Nature (Lond.). 371:606-609.

40. Sell, D.R., and V.M. Monnier. 1990. End-stage renal disease and diabetes catalyze the formation of a pentose-derived crosslink from aging human collagen. J. Clin. Invest. 85:380-384. 